\title{
Complementary alternative medicine use among patients with type 2 diabetes mellitus in the primary care setting: a cross-sectional study in Malaysia
}

\author{
Siew Mooi Ching ${ }^{1 *}$, Zainul Amiruddin Zakaria ${ }^{2}$, Fuziah Paimin ${ }^{3}$ and Mehrdad Jalalian ${ }^{4}$
}

\begin{abstract}
Background: Limited study on the use of complementary alternative medicine (CAM) among patients with diabetes mellitus (DM), particularly in primary -care settings. This study seeks to understand the prevalence, types, expenditures, attitudes, beliefs, and perceptions of CAM use among patients with DM visiting outpatient primary care clinics.
\end{abstract}

Methods: This is a descriptive, cross-sectional study of 240 diabetic patients. CAM is defined as a group of diverse medical and healthcare systems, practices, and products that are not generally considered part of conventional Western medicine. Data analysis was done using SPSS v. 19 and multiple logistic regressions were used to identify predictors of CAM use.

Results: The prevalence of CAM use was 62.5 percent. Female were 1.8 times more likely than male in using CAM. Malays (75\%) were the most frequent users, followed Indians (18\%) and Chinese (6\%). Biological therapy (50.0\%) were the most widely used, followed by manipulative-body based systems (9.2\%), energy system (8.8\%), alternative medicine systems (4.6\%) and mind-body system (1.7\%). In biological therapy, a total of 30.4 percent, 24.2 percent, 13.3 percent, and 7.9 percent of diabetic patients consumed bitter gourd (Momordica Charantia), followed by Misai Kucing (Orthosiphon Stamineus Benth), garlic (Allium Sativum), and Sabah snake grass (Clinacanthus Nutans Lindau) respectively. The mean of the expenditure on CAM usage was RM $52.8 \pm 101.9$ (US \$16.9 \pm 32.5 ) per month. According to multiple logistic regression analyses, being Muslim (OR 5.258, 95 percent Cl 2.952-9.368) had significant positive association with CAM use.

Conclusions: The prevalence of CAM use was high among diabetics. Islam faith is predictor for CAM use among Type 2 DM patients. The most-common herbs used were bitter gourd (Momordica Charantia) and Misai Kucing (Orthosiphon Stamineus, Benth). Further studies on the anti-glycemic activity of the isolated compound may be needed in the future.

Keywords: Complementary alternative medicine, Diabetes mellitus, Primary care, Malaysia, Prevalence

\section{Background}

Complementary and alternative medicine (CAM) is defined as a group of diverse medical and healthcare systems, practices, and products that are not generally considered part of conventional Western medicine [1,2]. CAM use can be divided into five categories: biologicalbased therapies like herbal and dietary supplement; alternative medical systems like acupuncture or Ayurveda; energy therapies like Reiki; manipulative and body-based

\footnotetext{
* Correspondence: siewmooi@medic.upm.edu.my

'Department of Family Medicine, Faculty of Medicine and Health Sciences, Universiti Putra Malaysia, Serdang, Selangor 43400, Malaysia

Full list of author information is available at the end of the article
}

systems like chiropractic or massage; and mind-body interventions like tai chi or yoga [3].

CAM usage is common among patients with diabetes mellitus (DM). A better understanding of CAM use will help the medical profession be more vigilant and patientcentered, particularly during counseling sessions regarding proper use herbal remedies in the stream of modern medicine.

The prevalence of CAM usage among DM patients has a wide range (17-72.8 percent) due to different definitions in the studies [4]. Studies show that white middle-aged, being women, receiving higher education and those suffer from more than one chronic disease (especially metabolic, 
mental, and musculoskeletal disorders) are having a higher correlation with the use of CAM $[5,6]$.

Studies reported that herbal remedies, vitamins, spirituality, and exercise are common CAM therapies pursued by diabetics [4]. Among the herbal remedies, true cinnamon (Cinnamomum verum) is used commonly in the United States and Canada [7]. Bitter gourd (Momordica Charantia) and garlic (Allium Sativum) are predominantly used in India [8]. In Asia and Mediterranean, fenugreek (Trigonella Foenum Graecum) has been cultivated and used medicinally for thousands of years $[9,10]$. In Malaysia, there are 12,000 plants. However, only about 1,300 herbs have been found to have therapeutic benefits [11]. This indicates that local herbs were underutilized, as not much study has been done on useful local herbs in treating or controlling diabetes [12]. Studies actually show that CAM remedies can be an important component of health self-management, depending on the patient's financial resources, culture, and self-empowerment [13,14]. Therefore, this study was conducted to examine the prevalence, types, reasons, and expenditures devoted to CAM among DM patients attending an outpatient primary-care clinic in Malaysia.

\section{Methods}

\section{Setting}

This is a cross-sectional study of patients registered with the primary health care clinic at Salak in Sepang, Selangor, Malaysia. This clinic is run by a family medicine specialist and 10 medical officers.

\section{Inclusion criteria}

All registered diabetics more than age 18 and above and a minimum follow-up of three months at Klinik Kesihatan Salak, Sepang, were eligible for the study. The sample size was calculated by using Epi Info 6.0, based on the prevalence in local studies, which ranged from $50-56$ percent $[15,16]$. The estimated sample size was 185 with 90 percent power, 95 percent confidence interval $(\mathrm{CI})$, and statistical significant level $(\alpha)$ at 5 percent. The total number of respondents needed was 240 , after taking into account a non-respondent rate of 30 percent. Patients were selected using a random sampling method. The estimated number of diabetic patients that visit the clinic per day and in three weeks' time were 32 patients and 480 patients. Since the number of required test subjects was 240 , the sampling interval of two was used as the constant difference between subjects. The first starting number of 2 was picked randomly from the registration counter.

\section{Data collection}

A face-to-face interview was conducted using a structured questionnaire. A written informed consent for participation in the study was obtained from participants.
The questionnaire was designed to capture patients' socio-demographic data, co-morbidities, types of CAM used, resources consulted, and the total expenditure on CAM. The attitudes, beliefs, and perceptions towards CAM were explored. Documented most-recent results of glycosylated hemoglobin (HbA1C) and blood pressure (BP) tests from the preceding year were captured from the patients' medical records. A pilot study involving 42 patients was done to pretest the questionnaire and estimate the likely response rate. The main survey was administered during the first three weeks of May 2011 by three medical students.

\section{Practical definition}

A DM patient was defined as someone who was clinically diagnosed with diabetes or was taking diabetic medications. Patients with hypertension were those whose $\mathrm{BP} \geq 140 / 90 \mathrm{mmHg}$ or were on antihypertensive agents.

CAM use in this study is defined as consumption in one of the five categories therapy: biological-based therapies like herbal and dietary supplement; alternative medical systems, like acupuncture or Ayurveda; energy therapies like Reiki; manipulative and body-based systems like chiropractic or massage; and mind-body interventions like tai chi or yoga [3].

\section{Data analysis}

Statistical Package for Social Sciences (SPSS) v. 19.0 was used to analyze the data collected from the study. The findings were described in terms of frequencies, percentages, means, and standard deviations. The association between socio-demographic factors (gender, age, race, religion, educational, occupation, family household income, and duration and control of diabetes) and the CAM usage was determined by using Chi-square test. Multivariate logistic regressions were used to identify predictors of CAM usage.

\section{Ethical approval}

Ethical approval was obtained from the Ethics Committee of National Malaysia Research Registry (NMRR-12430-11052).

\section{Results}

\section{Socio-demographic characteristics}

A total of 252 subjects was eligible in the original cohort; 12 of them refused to participate in the study. In the end, 240 diabetic patients were enrolled into the study with the response rate of 95 percent. Table 1 shows the socio-demographic information of respondents. The respondents were predominantly female Malayan Muslims $50-69$ years old with a mean age of $55.14 \pm 10$ years. Most received primary education and the average monthly household income was RM $1843.17 \pm 1537$ (USD 588). The mean 
Table 1 Demographic and clinical characteristics of the diabetic respondents in Klinik Kesihatan Salak $(\mathrm{N}=\mathbf{2 4 0})$

\begin{tabular}{|c|c|c|}
\hline Socio-demographic factors & $\begin{array}{l}\text { Total subject } \\
\mathrm{N}=240,(\%)\end{array}$ & $\begin{array}{l}\text { Using CAM } \\
\mathrm{n}=150,(\%)\end{array}$ \\
\hline \multicolumn{3}{|l|}{ Gender } \\
\hline Male & 95(39.6) & $54(36.0)$ \\
\hline Female & $145(60.4)$ & $96(64.0)$ \\
\hline \multicolumn{3}{|l|}{ Race } \\
\hline Malays & $145(60.4)$ & $112(74.7)$ \\
\hline Chinese & $14(5.8)$ & $9(6.0)$ \\
\hline Indians & $79(32.9)$ & $27(18.0)$ \\
\hline \multicolumn{3}{|l|}{ Religion } \\
\hline Muslim & $150(62.5)$ & $116(77.3)$ \\
\hline Buddhist & $13(5.4)$ & $8(5.4)$ \\
\hline Hindu & $71(29.6)$ & $24(16.0)$ \\
\hline Christian & $6(2.5)$ & $2(1.3)$ \\
\hline \multicolumn{3}{|l|}{ Level of Education } \\
\hline No education & $31(12.9)$ & $18(12.0)$ \\
\hline Primary & $99(41.2)$ & $57(38.0)$ \\
\hline Secondary & $94(39.2)$ & $64(42.7)$ \\
\hline Tertiary & $16(6.7)$ & $11(7.3)$ \\
\hline \multicolumn{3}{|l|}{ Occupation } \\
\hline Blue collar & $101(42.1)$ & $52(34.7)$ \\
\hline White collar & 139(57.9) & $98(65.3)$ \\
\hline \multicolumn{3}{|l|}{ Family Household Income } \\
\hline $0-2500$ & 189(78.8) & $116(77.3)$ \\
\hline $2501-5000$ & $44(18.3)$ & $29(19.3)$ \\
\hline $5001-7500$ & $3(1.2)$ & $1(0.4)$ \\
\hline 7501-10000 & $4(1.7)$ & $4(1.7)$ \\
\hline
\end{tabular}

duration of diabetes and the mean HbA1c were $6.5 \pm 5.7$ years and $8.7 \pm 2.8$ percent respectively. Most respondents (72.9 percent) had underlying hypertension followed by dyslipidemia (11.3 percent), asthma (1.7 percent), and osteoarthritis ( 0.8 percent). The mean systolic and diastolic blood pressures were $138 \pm 19$ and $82 \pm 12 \mathrm{mmHg}$, respectively.

\section{Types of CAM used by DM patients}

The prevalence of CAM use was 62.5 percent. Female were 1.8 times more likely than male. Malays $(75 \%)$ were the most frequent users, followed Indians (18\%) and Chinese (6\%). Table 2 shows CAM use among DM patients. Biological therapy which involved the herbal products $(50.0 \%)$ were the most widely used, followed by manipulative-body based systems (9.2\%), energy system (8.8\%), alternative medicine systems $(4.6 \%)$ and mind-body system (1.7\%). Bitter gourd (30.4 percent, $n=73$ ) was the most popular natural product consumed by respondents. Other commonly used herbal products included Misai Kuching (24.2 percent,
Table 2 Type of CAM used by DM patients in Klinik Kesihatan Salak $(\mathbf{N}=\mathbf{1 5 0})$

\begin{tabular}{lcc}
\hline Type of CAM & Frequency & Percentage \\
\hline Biological based therapy & $\mathbf{1 2 0}$ & $\mathbf{8 0 . 0}$ \\
like Herbal products & 73 & 48.7 \\
Bitter gourd & 58 & 38.7 \\
Misai Kuching & 32 & 21.3 \\
Garlic & 19 & 12.7 \\
Sabah snake grass & 5 & 3.3 \\
Basil leaf & 4 & 2.7 \\
Ginseng & $\mathbf{2 2}$ & $\mathbf{1 4 . 7}$ \\
Manipulative and body-based systems & 22 & 14.7 \\
Reflexology & $\mathbf{1 1}$ & $\mathbf{7 . 3}$ \\
Alternative medical systems & 10 & 6.7 \\
Ayurveda & 3 & 2.0 \\
Acupuncture & $\mathbf{2 1}$ & $\mathbf{1 4 . 0}$ \\
Energy therapies & 3 & 2.0 \\
Reiki & 18 & 12.0 \\
Massage bed & $\mathbf{4}$ & $\mathbf{2 . 7}$ \\
Mind-body interventions & 4 & 2.7 \\
Yoga/tai chi & & \\
\hline
\end{tabular}

$\mathrm{n}=58$ ) and garlic (13.3 percent, $\mathrm{n}=32$ ). Surprisingly, none of them sought help from a religion master and/or "bomoh."

\section{Attitudes, beliefs, and perceptions toward CAM}

More than half of survey respondents pursued CAM therapies because they believed CAM can help them achieve better control in diabetes ( 58.0 percent) and better value for money (17.3 percent). Some use it because they are following the example of other CAM users (17.3 percent) (Table 3).

\section{Resources on CAM}

This study found that most respondents learned about CAM primarily from friends (32.1 percent) and family (13.8 percent) followed by media (13.3 percent) and health professionals. The mean duration of CAM usage was $4.0 \pm 4.6$ years. The mean frequency of consumption was 3.5 times per week.

\section{Expenditures on CAM}

The mean of the total out-of-pocket expenditure on CAM usage was RM $52.8 \pm 101.9$ (US $\$ 16.9 \pm 32.5$ ) per month. The vast majority (87.5 percent) of respondents spent RM 52.8 (US\$16.9) or less per month on CAM. Thirty patients (12.5 percent) spent more than RM 52.8 (US\$16.9) per month on CAM therapies. 
Table 3 Attitudes, beliefs, and perceptions questionnaires toward CAM ( $\mathrm{N}=150)$

\begin{tabular}{lll}
\hline $\begin{array}{l}\text { Attitudes, beliefs and perceptions towards } \\
\text { complementary alternative medicine }\end{array}$ & $\mathbf{n}$ & $\%$ \\
\hline Believe CAM can help the diabetes control & 87 & 58.0 \\
$\begin{array}{l}\text { Having good example from the other user } \\
\text { of CAM and keen to share with others }\end{array}$ & 26 & 17.3 \\
Easily available and better value for money & 26 & 17.3 \\
Dissatisfied with western medicines & 5 & 3.3 \\
Use for other co morbidity treatment & 5 & 3.3 \\
Believed that CAM had fewer side effects & 1 & 0.7 \\
\hline
\end{tabular}

\section{Multivariate logistic regression}

Table 4 summarizes the characteristic differences between CAM users and non-CAM users. The results of unadjusted univariate logistic regression analysis of variables related to CAM users were calculated. A multivariate logistic regression analysis was used to independently predict a CAM user after adjustment for variables that attained $\mathrm{P}<0.05$ in univariate analysis and clinical

Table 4 Association of characteristics between patients who used CAM and those who did not use CAM ( $N=240)$

\begin{tabular}{|c|c|c|c|}
\hline Socio-demographic factors & $\begin{array}{l}\text { No CAM use } \\
n=90,(\%)\end{array}$ & $\begin{array}{l}\text { CAM use } \\
n=150,(\%)\end{array}$ & p-value \\
\hline \multicolumn{4}{|l|}{ Gender } \\
\hline Male & $41(45.6)$ & $54(36.0)$ & 0.163 \\
\hline Female & $49(54.4)$ & $96(64.0)$ & \\
\hline \multicolumn{4}{|l|}{ Ethnicity } \\
\hline Malays & $33(36.7)$ & $112(74.7)$ & $<0.001$ \\
\hline Chinese & $5(5.6)$ & $9(6.0)$ & \\
\hline Indians & $52(57.8)$ & $27(18)$ & \\
\hline \multicolumn{4}{|l|}{ Religion } \\
\hline Islam & $34(37.8)$ & $116(77.3)$ & $<0.001$ \\
\hline Buddhist & $5(5.6)$ & $8(5.3)$ & \\
\hline Hindu & $47(52.2)$ & $24(16.0)$ & \\
\hline Christian & $4(4.4)$ & $2(1.3)$ & \\
\hline \multicolumn{4}{|l|}{ Education } \\
\hline Primary school and below & $55(61.1)$ & $75(50.0)$ & 0.115 \\
\hline Secondary school and above & $35(38.9)$ & $75(50.0)$ & \\
\hline \multicolumn{4}{|l|}{ Occupation } \\
\hline Blue collar & $48(53.3)$ & $52(34.7)$ & 0.005 \\
\hline Non Blue collar & $42(46.7)$ & $98(65.3)$ & \\
\hline Hypertension & $63(70.0)$ & $112(74.7)$ & 0.431 \\
\hline Family Household Income (n, SD) & $1536 \pm 1236$ & $2030 \pm 1666$ & 0.019 \\
\hline $\mathrm{HbA} 1 \mathrm{c}(\mathrm{n}, \mathrm{SD})$ & $8.5 \pm 1.7$ & $8.9 \pm 3.0$ & 0.448 \\
\hline
\end{tabular}

There is significant association if $\mathrm{p}$-value $<0.05 *$.

CAM: complementary alternative medicine.

$S D$ : standard deviation.

$n=$ number. significant variables. Being Muslim (odds ratio [OR] 5.258, 95 percent, CI 2.952-9.368) is the only predictor for CAM use after adjustments for gender, ethnicity, religion, occupation, family household income and hypertension.

\section{Discussion}

The prevalence of CAM usage among DM patients in this study population was high (62.5 percent). This is consistent with findings in other studies [4]. The current usage is higher than studies in the United Kingdom (17 percent) [17], Australia (23.6 percent) [18], Turkey (41.0 percent) [19], and Thailand (47 percent) [20]. This is comparable to studies in Taiwan (61 percent) [21] and Mexico (62 percent) [22] and lower compared to Korea (65 percent) [23], India (67.7 percent) [24], and the U.S. (72.8 percent) [25]. Our results were much higher compared to the local population study, where only 2.3 percent of Malaysians consumed CAM overall [26] and 0.2 percent of DM patients had experience in using CAM [27]. However, this may be underreported as other studies mention that patients with chronic diseases like diabetes tend to consume CAM compared to the general population $[4,7,25,28,29]$. Our result is still higher when compared to the two other local studies done at the Ipoh primary care clinic (56 percent) and Seremban Government Hospital diabetes health clinic (49.6 percent) respectively [15,16].

Previous studies reported that the reasons for DM patients to choose such therapies may be related to the fact that diabetes is a chronic, devastating, and incurable disease. Patients may have positive views of CAM due to its organic nature (which can present fewer side-effects), concerns about doctors' listening skills, preferences to be treated holistically, and increased availability of CAM $[10,30]$.

In the present study, only a small portion of patients were dissatisfied with conventional medicines (3.3 percent) and believed that traditional medicine presented more adverse effects ( 0.7 percent). This was surprising, since previous studies had shown dissatisfaction with conventional treatments due to ineffectiveness or unpleasant side effects were the common reasons for pursuing CAM. This is consistent with a US-based study that reported "users of alternative health care are no more dissatisfied with or distrustful of the conventional care than nonusers are" [10]. One possible reason for our findings is a change in society that links to a patient self-empowerment paradigm [31]. Most DM patients had poor blood-sugar control, as the conventional treatment requires them to be disciplined with respect to diet, lifestyle, and behavior [32,33]. Because of this, patients tend to try CAM to optimize their health status so that they feel that they have partially contributed to the management of their disease. They believe CAM offers 
more personal autonomy and control over their disease [34-36]. On the other hand, it could be related to underlying shared beliefs and cultural assumptions [37].

In our study, the main types of CAM used were herbal and dietary supplements as well as reflexology. The high consumption is not surprising, since most diabetics presumed that herbs are safer and, additionally, more affordable and easily available $[16,38,39]$. This was further supported by the fact that the total out-of-pocket expenditure was RM $52.8 \pm 101.9$ (US \$17.0 \pm USD32.8) per month. The most common sources of CAM information were recommendation from friends and families. The present study indicates that we must involve patients' friends and the families during diabetes education counseling regarding the efficacy and potential sideeffects of CAM.

Malaysia is a multiethnic, multicultural, multi-religious developing nation in which Malays form the majority, constituting 50.4 percent of the population [40]. CAM use is deeply rooted and influenced by its multicultural and religious nature. It has had ethnic diversity and this influences CAM use as well. Uses of herbs [41] like bitter gourd [42-44], Misai Kucing (Orthosiphon Stamineus Benth) $[45,46]$, garlic (Allium Sativum) $[47,48]$, and ginseng (Panax Ginseng) [49] are believed to reduce blood sugar levels. Bitter gourd [50], also known as Momordica Charantia is a tropical vine that is widely believed to bring down blood sugar levels, despite a lack of robust evidence $[43,44,50-52]$. Bitter gourd was widely used as ayuverda treatment in India. It was found to be the most common herb used as before $15^{\text {th }}$ century and traditional Malay medicine has been strongly influenced by the animistic culture of Hindu-Buddhism, thus the use of the bitter gourd is already deeply ingrained in the Malay population [26].

Interestingly, Sabah snake grass (Clinacanthus Nutans Lindau), an anti-inflammatory used for treating insect bites and herpes infections in Thailand [53], has also been widely used by DM patients. The users believe it contains anti-glycemic components. This may merit further study.

Belief in Islam was found to be one of the strongest predictors for pursuing CAM therapy. One explanation for this may be that CAM usage has always been embedded into the Muslim belief system and cultural heritage that is already deeply integrated into their lives $[54,55]$. Indeed, Malaysia is unique in its role as a confluence of three Asian cultures, giving rise to three main traditional healing practitioners. However, Malaysia is an Islamic country, so this may explain why only a belief in the Muslim religion is a predictor of CAM usage.

Older female patients with higher levels of education and household income were more likely to be CAM users in some studies [56-58]. However, the present study found no significant relationship in CAM usage and gender, mean age, ethnic group, education level, or total household income. This could be because the studied population was DM patients, who might be more likely to resort to CAM therapies - regardless of gender or socio-demographic status. This is supported by a U.S.based study that reported that DM patients were 1.6 times more likely to use CAM than non-diabetics [58]. The $\mathrm{HbA1C}$ also was not found to have relationship as the control of diabetes was confounded by other factors such as compliance as well as other treatment modalities. This is important because, although there is increasing global interest in CAM use worldwide, doctors who practice Western medicine seem less aware about its significance and importance. By right, as health-care professionals, we should be knowledgeable about potential benefits and possible toxicities of such remedies [59]. Practitioners should provide evidence-based information on safety issues, efficacy, and potential interactions among commonly used CAM treatments - instead of brushing the topic aside or ignoring its usage.

\section{Strength and limitations}

This will be interesting to include non-diabetic group as the control group in this study. However, it was not done due to the time constraint. Enquiry into the number of prescribed medication is important but not done in this study as this is not the primary objective. It is acknowledged that a comparison of rates of CAM use among DM patients across different studies is limited due to the differences in the definitions and inclusions/ exclusions of CAM therapies in each study. However, these will not affect our findings in any way.

\section{Conclusions}

This study showed that the prevalence of CAM consumption/use was higher among DM patients. The high consumption/use of CAM should prompt clinicians to further explore this topic, particularly among DM patients who are Muslim. In addition, future studies are recommended to conduct a randomization trial that analyzes these herbs particularly bitter gourd, Misai Kuching, garlic, and sabah snake grass - in reducing blood sugar levels in local settings.

\section{Abbreviations}

CAM: Complementary alternative medicine; BP: Blood pressure; DM: Diabetes mellitus; SPSS: Statistical package for social sciences; HbA1C: Glycosylated hemoglobin; USD: United States dollar; RM: Ringgit Malaysia; OR: Odds ratio; $\mathrm{Cl}$ : Confidence interval.

\section{Competing interests}

The authors declare that they have no competing interests. 


\section{Authors' contributions}

SMC and FP involved in the study design, data collection, performed the statistical analysis and drafted manuscript. ZAZ and MJ helped to design the study and drafting the manuscript. All authors read and approved the final manuscript.

\section{Acknowledgements}

The author would like to acknowledge the Sepang District Health Office and Director of Health for their support of our study. The author would like to thank David Lee Han Hong, Nur Farahin bt Mohd Din, Tan Soo Ying, and the clinical staffs for providing support during the data collection. The authors also acknowledge late Dr. Zaiton Ahmad for her contribution to the early stages of this study.

\section{Author details}

${ }^{1}$ Department of Family Medicine, Faculty of Medicine and Health Sciences, Universiti Putra Malaysia, Serdang, Selangor 43400, Malaysia. ²Department of Biomedical Science, Faculty of Medicine and Health Sciences, Universiti Putra Malaysia, Serdang, Selangor 43400, Malaysia. ${ }^{3}$ Family medicine specialist, Klinik Kesihatan Salak, Sepang, Malaysia. ${ }^{4}$ M.D., Mashhad, Iran.

Received: 23 January 2013 Accepted: 20 June 2013

Published: 26 June 2013

\section{References}

1. What is Complementary and Alternative Medicine?. Accessed 8th January 2013 [http://cim.ucdavis.edu/clubs/camsig/whatiscam.pdf]

2. Traditional Medicine Growing Needs and Potential - WHO Policy Perspectives on Medicines, No. 002, May 2002. Accessed 8th January 2013 [http://apps. who.int/medicinedocs/en/d/Js2293e/]

3. Barnes PM, Powell-Griner E, McFann K, Nahin RL: Complementary and alternative medicine use among adults: United States, 2002. Adv Data 2004, 343:1-19.

4. Chang HY, Wallis M, Tiralongo E: Use of complementary and alternative medicine among people living with diabetes: literature review. J Adv Nurs 2007, 58:307-319.

5. Lee GBW, Charn TC, Chew ZH, Ng TP: Complementary and alternative medicine use in patients with chronic diseases in primary care is associated with perceived quality of care and cultural beliefs. Fam Pract 2004, 21:654-660.

6. Bausell RB, Lee WL, Berman BM: Demographic and health-related correlates to visits to complementary and alternative medical providers. Med Care 2001, 39:190-196

7. Nahas R, Moher M: Complementary and alternative medicine for the treatment of type 2 diabetes. Can Fam Physician 2009, 55:591-596.

8. Modak M, Dixit P, Londhe J, Ghaskadbi S, Paul A, Devasagayam T: Indian herbs and herbal drugs used for the treatment of diabetes. J Clin Biochem Nutr 2007, 40:163-173.

9. Al-Saeedi M, Elzubier AG, Bahnassi AA, Al-Dawood KM: Patterns of belief and use of traditional remedies by diabetic patients in Mecca, Saudi Arabia. East Mediterr Health J 2003, 9:99-107.

10. Astin JA: Why patients use alternative medicine: results of a national study. JAMA 1998, 279:1548-1553.

11. Jamal $P$, Barkat AA, Amid A: Distribution of phenolics in various Malaysian medicinal plants. J App/ Sci 2010, 10:2658-2662.

12. Ibrahim J: The scientific values of Malaysian herbal products. Jurnal Sains Kesihatan Malaysia 2006, 4:59-70.

13. Grzywacz JG, Lang W, Suerken C, Quandt SA, Bell RA, Arcury TA: Age, race, and ethnicity in the use of complementary and alternative medicine for health self-management: evidence from the 2002 National Health Interview Survey. J Aging Health 2005, 17:547-572.

14. McMahan S, Lutz R: Alternative therapy use among the young-old (Ages 65 to 74): an evaluation of the MIDUS database. J Appl Gerontol 2004, 23:91-103.

15. Remli R, Chan SC: Use of complementary medicine amongst diabetic patients in a public primary care clinic in Ipoh. Med J Malaysia 2003, 58:688-693.

16. Hasan SS, Loon WC, Ahmadi K, Ahmed SI, Bukhari NI: Reasons, perceived efficacy and factors associated with complementary and alternative medicine use among Malaysian patients with diabetes mellitus. Br J Diabetes Vasc Dis 2011, 11:92-98.
17. Leese GP, Gill GV, Houghton GM: Prevalence of complementary medicine usage within a diabetes clinic. Practical Diabetes 1997, 14:207-208.

18. Clifford RM, Davis TM, Batty KT, Davis W: Prevalence and predictors of complementary medicine usage in diabetes: fremantle diabetes study. J Pharm Pract Res 2003, 33:260-264

19. Ceylan S, Azal O, Taşlipinar A, Türker T, Açikel CH, Gulec M: Complementary and alternative medicine use among Turkish diabetes patients. Complement Ther Med 2009, 17:78-83.

20. Moolasarn S, Sripa S, Kuessirikiet V, Sutawee K, Huasary J, Chaisila C, Chechom N, Sankan S: Usage of and cost of complementary/alternative medicine in diabetic patients. J Med Assoc Thai 2005, 88:1630-1637.

21. Chang $\mathrm{HA}$, Wallis $\mathrm{M}$, Tiralongo $\mathrm{E}$ : Use of complementary and alternative medicine among people with type 2 diabetes in Taiwan: a crosssectional survey. Evid Based Complement Alternat Med 2011, 2010:1-8

22. Argáez-López N, Wacher NH, Kumate-Rodríguez J, Cruz M, Talavera J, Rivera-Arce E, Lozoya X, DIMSS study Group: The use of complementary and alternative medicine therapies in type 2 diabetic patients in Mexico. Diabetes Care 2003, 26:2470-2471

23. Lee MS, Lim HJ, Moon SR: Survey of the use of complementary and alternative medicine among Korean diabetes mellitus patients. Pharmacoepidemiol Drug Saf 2004, 13:167-171.

24. Kumar D, Bajaj S, Mehrotra R: Knowledge, attitude and practice of complementary and alternative medicines for diabetes. Public Health 2006, 120:705-711.

25. Bell RA, Suerken CK, Grzywacz JG, Lang W, Quandt SA, Arcury TA: Complementary and alternative medicine use among adults with diabetes in the United States. Altern Ther Health Med 2006, 12:16-22.

26. National Policy on Traditional/Complementary medicine. Accessed 8th August 2012 [http://www.mps.org.my/newsmaster.cfm?\&menuid=37\&action=view\& retrieveid $=1134$

27. Institute for Public Health (IPH): National Health and Morbidity Survey 2011 (NHMS 2011). Non-Communicable Diseases 2011, II:188.

28. Hasan SS, Ahmed SI, Bukhari NI, Loon WC: Use of complementary and alternative medicine among patients with chronic diseases at outpatient clinics. Complement Ther Clin Pract 2009, 15:152-157.

29. Dunning T: Complementary therapies and diabetes. Complement Ther Nurs Midwifery 2003, 9:74-80

30. Vincent C, Furnham A: Why do patients turn to complementary medicine? An empirical study. Br J Clin Psychol 1996, 35:37-48.

31. The World Health Report 2000-Health Systems: Improving Performance. Accessed 8th January 2013 [http://www.who.int/whr/2000/]

32. Muela SH, Mushi AK, Ribera JM: The paradox of the cost and affordability of traditional and government health services in Tanzania. Health Policy Plan 2000, 15:296-302

33. Funnell MM, Anderson RM: Empowerment and self-management of diabetes. Clinical Diabetes 2004, 22:123-127.

34. Engel LW, Straus SE: Development of therapeutics: opportunities within complementary and alternative medicine. Nat Rev Drug Discov 2002, 1:229-236

35. Dunning T, Chan SP, Hew FL, Pendek R, Mohd MA, Ward G: Transcultural therapy: a cautionary tale on the use of complementary therapies. Diabetes Primary Care 2001, 3:58-63.

36. Chatzimarkakis J: Why patients should be more empowered: a European perspective on lessons learned in the management of diabetes. J Diabetes Sci Technol 2010, 4:1570-1573.

37. Arcury TA, Bell RA, Snively BM, Smith SL, Skelly AH, Wetmore LK, Quandt SA: Complementary and alternative medicine use as health selfmanagement: rural older adults with diabetes. J Gerontol B Psychol Sci Soc Sci 2006, 61:S62-S70

38. Dannemann K, Hecker W, Haberland H, Herbst A, Galler A, Schäfer T, Brähler E, Kiess W, Kapellen TM: Use of complementary and alternative medicine in children with type 1 diabetes mellitus - prevalence, patterns of use, and costs. Pediatr Diabetes 2008, 9:228-235.

39. Kaptchuk TJ, Eisenberg DM: The persuasive appeal of alternative medicine. Ann Intern Med 1998, 129:1061-1065.

40. Population and Housing Census 2000-Department of Statistics; 2013. Assessed on 8th January 2013 [http://www.statistics.gov.my/portal/index.php? option=com content\&id=352\&ltemid=111\&lang=en]

41. Yeh GY, Eisenberg DM, Kaptchuk TJ, Phillips RS: Systematic review of herbs and dietary supplements for glycemic control in diabetes. Diabetes Care 2003, 26:1277-1294 
42. Baldwa VS, Bhandari CM, Pangaria A, Goyal RK: Clinical trial in patients with diabetes mellitus of an insulin-like compound obtained from plant source. Ups J Med Sci 1977, 82:39-41.

43. Basch E, Gabardi S, Ulbricht C: Bitter melon (Momordica charantia): a review of efficacy and safety. Am J Health Syst Pharm 2003, 60:356-359.

44. Welihinda J, Karunanayake EH, Sheriff MHH, Jayasinghe KSA: Effect of Momordica charantia on the glucose tolerance in maturity onset diabetes. J Ethnopharmacol 1986, 17:277-282.

45. Mohamed EA, Mohamed AJ, Asmawi MZ, Sadikun A, Ebrika OS, Yam MF: Antihyperglycemic effect of Orthosiphon stamineus benth leaves extract and its bioassay-guided fractions. Molecules 2011, 16:3787-3801.

46. Misai Kucing-Mardi. Accessed 8th January 2013 [http://agromedia.mardi.gov. my/MEPIS/index.php/galeri-herba-2/88-misai-kucing]

47. Ballali S, Lanciai F: Functional food and diabetes: a natural way in diabetes prevention? Int J Food Sci Nutr 2012, 63:51-61.

48. Ashraf R, Khan RA, Ashraf I: Garlic (Allium sativum) supplementation with standard antidiabetic agent provides better diabetic control in type 2 diabetes patients. Pak J Pharm Sci 2011, 24:565-570.

49. Sievenpiper JL, Arnason JT, Vidgen E, Leiter LA, Vuksan V: A systematic quantitative analysis of the literature of the high variability in ginseng (Panax spp.). Diabetes Care 2004, 27:839-840.

50. Blum A, Loerz C, Martin H-J, Staab-Weijnitz CA, Maser E: Momordica charantia extract, a herbal remedy for type 2 diabetes, contains a specific $11 \beta$-hydroxysteroid dehydrogenase type 1 inhibitor. I Steroid Biochem Mol Biol 2012, 128:51-55.

51. Dans AML, Villarruz MVC, Jimeno CA, Javelosa MAU, Chua J, Bautista R, Velez GG: The effect of Momordica charantia capsule preparation on glycemic control in type 2 diabetes mellitus needs further studies. $J$ Clin Epidemiol 2007, 60:554-559.

52. Ooi CP, Yassin Z, Hamid TA: Momordica charantia for type 2 diabetes mellitus. Cochrane Database Syst Rev 2012, 8, CD007845.

53. Sakdarat S, Shuyprom A, Ayudhya TDN, Waterman PG, Karagianis G: Chemical composition investigation of the Clinacanthus nutans Lindau leaves. Thai J Phytopharm 2006, 13(2):13-24

54. Hutch RA: Health and Healing: Spiritual, Pharmaceutical and Mechanical Medicine. J Relig Health 2011, 27:1-11. doi:10.1007/s10943011-9545-X.

55. Micozzi MS: Fundamentals of Complementary and Integrative Medicine. 3rd edition. Saunders: Elsevier; 2005

56. Lim MK, Sadarangani P, Chan HL, Heng JY: Complementary and alternative medicine use in multiracial Singapore. Complement Ther Med 2005, 13:16-24.

57. Aziz Z, Tey NP: Herbal medicines: prevalence and predictors of use among Malaysian adults. Complement Ther Med 2009, 17:44-50.

58. Egede $L E$, Ye $X$, Zheng D, Silverstein MD: The prevalence and pattern of complementary and alternative medicine use in individuals with diabetes. Diabetes Care 2002, 25:324-329.

59. Merican I: Traditional/complementary medicine: the way ahead. Med J Malaysia 2002, 57:261-265.

doi:10.1186/1472-6882-13-148

Cite this article as: Ching et al:: Complementary alternative medicine use among patients with type 2 diabetes mellitus in the primary care setting: a cross-sectional study in Malaysia. BMC Complementary and Alternative Medicine 2013 13:148.

\section{Submit your next manuscript to BioMed Central and take full advantage of:}

- Convenient online submission

- Thorough peer review

- No space constraints or color figure charges

- Immediate publication on acceptance

- Inclusion in PubMed, CAS, Scopus and Google Scholar

- Research which is freely available for redistribution

Submit your manuscript at www.biomedcentral.com/submit 